\title{
A novel tool monitoring approach for diamond wire sawing
}

\author{
Berend Denkena ${ }^{1} \cdot$ Benjamin Bergmann ${ }^{1} \cdot$ Björn-Holger Rahner ${ }^{1}$
}

Received: 16 September 2021 / Accepted: 22 October 2021 / Published online: 10 November 2021

(c) The Author(s) 2021

\begin{abstract}
Mobile diamond wire sawing is a highly flexible, productive and, versatile cutting process. Accordingly, it is used in many areas, such as the dismantling of nuclear power plants or wind turbines. Despite the widespread use of the process, the cutting process requires continuous manual monitoring by the machine operator. This is due to the continuously changing cutting conditions. A common process error is tool breakage. It is often caused by the displacement of the grinding segments (cutting beads). Due to the cutting speed (up to $30 \mathrm{~m} / \mathrm{s}$ ), these failures cannot be detected and prevented by the machine operator. However, a measuring system or process monitoring does not exist yet. Accordingly, a damaged diamond wire can become hooked, which often results in wire breaks. As a result, grinding segments break away from the wire, which can lead to deadly accidents. Therefore, a new approach for monitoring the tool for diamond wire grinding will be investigated. The paper is divided into five sections. First, the requirements for the sensor system are derived. After the selection of a measuring principle and the functional verification in the grinding process, the monitoring approach is presented and features for monitoring the tool with regard to the displacement of grinding segments are described. It was shown that the developed approach is suitable for monitoring the diamond wire tool during the sawing process. The investigation on a prepared diamond wire tool also demonstrated that the feature allows the detection of displacing grinding segments already from $2 \mathrm{~mm}$.
\end{abstract}

Keywords Process monitoring $\cdot$ Diamond wire sawing $\cdot$ Eddy current $\cdot$ Grinding segments $\cdot$ Machine technologie $\cdot$ Cutting beads

\section{Introduction}

Diamond wire sawing is a cut-off grinding process whose source is found in rock extraction from quarries [1]. Today, mobile diamond wire sawing is used for numerous applications like the dismantling of nuclear facilities and steel constructions [2-4]. The process is also widely used in the construction industry [5]. Compared to processes (e.g. wall saw), diamond wire sawing offers a high degree of flexibility in terms of component geometry/volume and the range of materials that can be separated. The low space requirement, low set-up effort, and low noise emission are also advantages of diamond wire sawing [6, 7]. The schematic construction of a mobile diamond wire sawing machine is shown in Fig. 1. During the grinding process, the material is continuously removed from the workpiece. The drive roller

Björn-Holger Rahner

rahner@ifw.uni-hannover.de

1 Institute of Production Engineering and Machine Tools, Leibniz Universität Hannover, Hanover, Germany generates the relative movement between the tool and workpiece required for the grinding process (up to $30 \mathrm{~m} / \mathrm{s}$ [8]). To ensure the required contact between tool and workpiece, the diamond wire is pulled into the wire sawing machine by the force-controlled feed unit. Caused by the continuous cutting process, the engagement length of the diamond wire in the workpiece is shortened. The released diamond wire is drawn into the wire storage unit by the feed unit.

Figure 2 shows the structure of common diamond wire grinding tools. The grinding segments with the diameter $d_{\mathrm{s}}$ and the length $l_{\mathrm{s}}$ are threaded onto the flexible carrier wire. In between each grinding segment is a defined distance $l_{\mathrm{t}}$ $[1,9]$. The additional steel springs are used to prevent the segments from displacing. The applied rubber coating serves to protect the carrier wire and the springs. It also increases the adhesion of the individual components on the carrier wire. An endless wire tool is achieved by joining the ends of the wire. The structure of the common grinding segments is also illustrated in Fig. 2. Here, the diamonds required for grinding are fixed to the metallic sleeve by a bonding matrix. Thereby, a distinction is made between galvanic, 


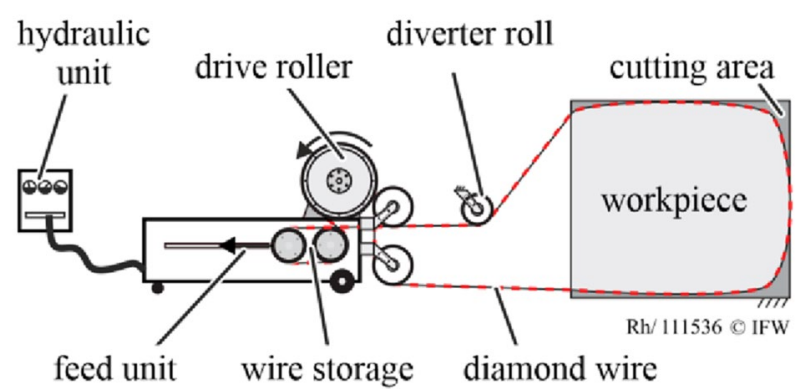

Fig. 1 General structure of a mobile wire saw

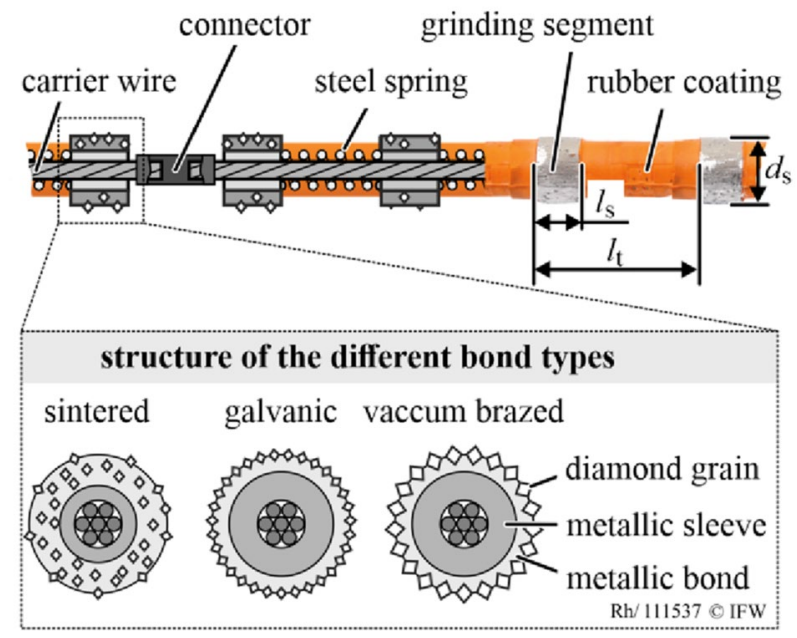

Fig. 2 Structure of common diamond wire tools

vacuum-brazed, and sintered bonding matrices. The bonding matrix is an important component in the tool structure. It must have sufficient strength to absorb and transmit the machining and centrifugal forces. For sintered tools, it is also important that sufficient bond removal is achieved so that self-sharpening occurs. Furthermore, all bond types must have sufficient thermal conductivity and chemical resistance [10].

Diamond wire sawing is characterised by constantly changing engagement conditions. The reasons for this are the grinding progress (change of the engagement length) and unpredictable material changes in the workpiece (cavities, concrete to steel, etc.). To ensure high productivity and avoid process errors, the operator must continuously adjust the wire tension and wire velocity depending on the process progress. Insufficient adaptation of the process parameters leads to process errors such as unilateral grinding segment wear or tool failure. In contrast to the unilateral grinding segment wear, tool failure represents a significant safety risk (e.g., whip effect). This can lead to serious and deadly accidents [11-13].
Tool failure can be subdivided into carrier wire breakage and displacement of the grinding segments on the carrier wire. Regardless of the reason, carrier wire breakage is generally defined as the loosening of the closed wire. Caused by the whip effect, grinding segments and the springs can detach from the carrier wire and fly through the air like bullets. In the natural stone industry, a breakage is often caused by fatigue of the carrier wire [11]. However, in the construction industry and the dismantling of power plants [6], which are the main application areas, the carrier wire breakage can be neglected due to the significantly shorter service life of the grinding segments. In the last mentioned application areas, the pull out of the carrier wire end from the connector is the main cause of a breakage. The reason for this is often incorrect crimping of the connections. Another reason is the clamping of the tool with the workpiece, which causes the end of the carrier wire to be torn out of the connector. Such rope breaks are not predictable and unavoidable [14].

A rope break, however, can be predicted because of because of the displaced grinding segments. The reason for the displacement of the grinding segments is the damage of the rubber coating $[6,14]$. As a result of the mechanical work (contact between tool and workpiece), the rubber coating detaches from the carrier wire. The wear of the rubber coating is supported by the thermal stress as a consequence of the cutting process [9]. Consequently, the rubber coating can no longer ensure the adhesion of the components [6]. Friction or catching of the tool on the workpiece (cavities, edges, ...) causes the grinding segments to slide. Accordingly, the end of the tool's usability is reached. If the displacement of the grinding segments remains unnoticed, the rope will break.

Since the displacement of the grinding segments is a continuous change in the tool structure, it can be monitored, unlike an abrupt wire break. To detect this process failure an intermittent manual inspection based on predefined operating times (1-2 $\mathrm{h}$ intervals [8]) is recommended. For this purpose, the process is stopped and the operator visually controls the accessible tool sections. The disadvantage of this procedure is the absence of process reliability, reduced productivity, and the fact that it is not possible to carry out a complete inspection of the entire rope. Tatzig presents the only known approach for the detection of displaced grinding segments. He showed that it is possible to detect displaced grinding segments in the frequency spectra of the force signal [6]. However, the approach is not suitable for use in mobile diamond wire grinding. This is because the workpiece was mounted on a force measurement platform. An adaption of this approach for different workpieces was not shown.

As can be seen from the state of the art, there is no approach to monitoring the diamond wire tool for use in mobile wire grinding. The manual and intermittent control 
through the operator does not allow reliable monitoring of the tool. Additionally, the detection of damage is significantly dependent on the experience and attention of the operator. The force-based monitoring approach presented is also not suitable. Hence, the paper presents a measurement approach that enables in-process monitoring of displacing grinding segments.

\section{Measuring principle selection}

For monitoring displacing grinding segments, a basic distinction must be made between a direct and indirect measuring method. In a direct measurement, the distance between two grinding segments is measured directly with the correct physical unit (c.f. caliper gauge). However, direct measurement is not possible due to accessibility during the cutting process. Consequently, an indirect measurement (auxiliary variable) must be carried out. The principal measurement approach is shown in Fig. 3. For this purpose, a radial positioning of the measuring system to the diamond wire tool is chosen. Moreover, the application of tactile measuring systems is excluded because of the high abrasiveness of the grinding segments, which leads to high wear. Accordingly, only non-contact measuring principles are considered.

A further limitation of possible non-contact measuring principles results from the tool cooling. Since water is often used in mobile wire sawing [8], the measuring principle must not be influenced by water, mud, or dust. Accordingly, optical and capacitive measuring principles cannot be used. Optical systems become polluted, whereas capacitive systems change their permittivity because of water, mud, or dust. Consequently, with both measuring principles, no robust measurement is possible under harsh environmental conditions. In contrast to optical and capacitive measuring principles, an inductive measurement is not influenced by the environmental conditions mentioned. In addition, the grinding segments (Fig. 2) consist of a metallic sleeve and a

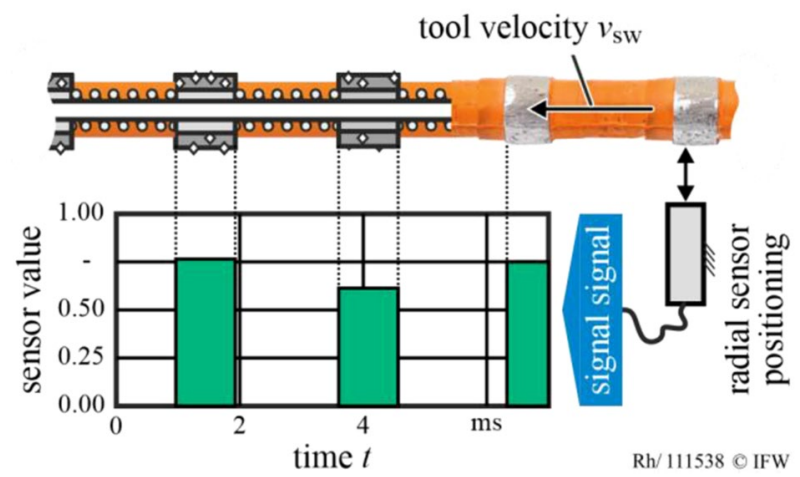

Fig. 3 Concept of the indirect tool measurement metallic bonding matrix, which are electrically conductive. Consequently, the detection of the grinding segments by using an inductive measuring principle is generally possible.

Another requirement is the sampling rate, which must be sufficiently high due to the tool velocity. To detect a displacement of grinding segments it is required that the beginning and the end of a grinding segment can be identified. Respectively, the rough estimated calculation of the sampling rate $f$, based on Eq. (1), results in a sampling rate of $15 \mathrm{kHz}$ for a common grinding segment $\left(l_{\mathrm{s}}=4 \mathrm{~mm}\right.$, tool velocity $\left.v_{\mathrm{s}}=30 \mathrm{~m} / \mathrm{s}\right)$. The factor of two serves to preserve the Nyquist-Shannon sampling theorem.

$f>2 \cdot \frac{v_{\mathrm{s}}}{l_{\mathrm{s}}}$.

Since inductive measuring principles achieve sufficiently high sampling rates $(>100 \mathrm{kHz})$ and are robust against the environmental conditions occurring during mobile wire sawing, an inductive measuring principle is chosen for further work.

\section{Test setup}

For the basic functional verification of the measurement principle, a single-axis rig was used. The test rig consists of a linear axis, which allows a moving range of $500 \mathrm{~mm}$. A Siemens $840 \mathrm{~d}$ sl is used to control the axis (Fig. 4). Hence, the sensor can be moved along the diamond wire tool with defined and constant boundary conditions. The sensor movement prevented influences such as wire vibrations, changing sensor distances, or velocity.

The experimental investigation with the moving diamond wire tool was carried out at test rig 2. For this purpose, the test setup shown in Fig. 5 was integrated into the FS 840 KT

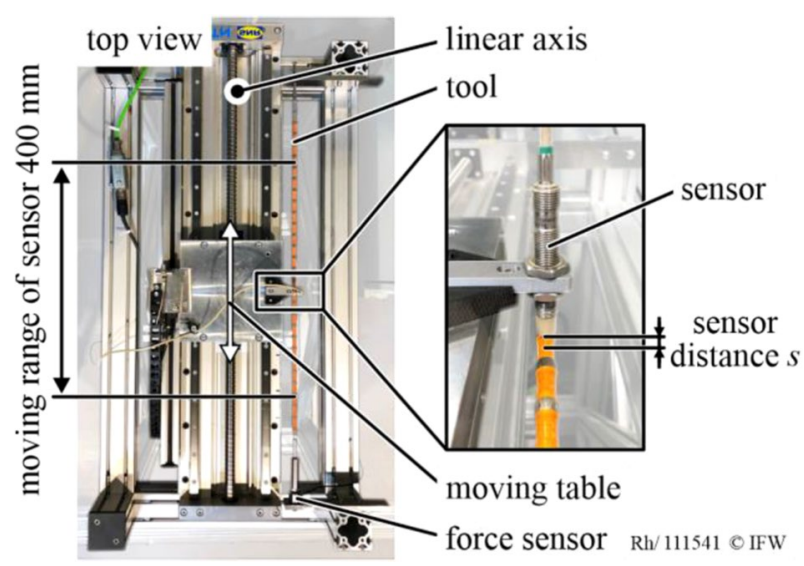

Fig. 4 Test rig 1: stationary wire, moving sensor 


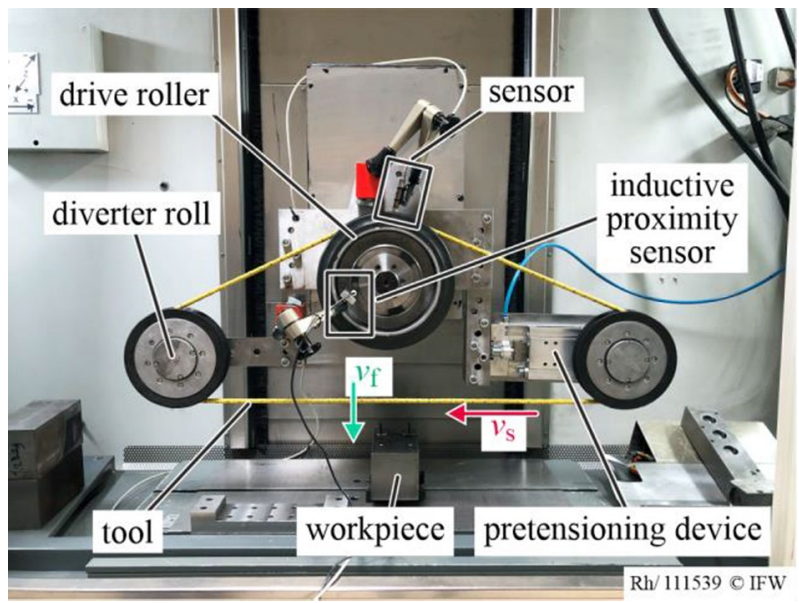

Fig. 5 Test rig 2: moving wire, stationary sensor

$\mathrm{CNC}$ (surface grinding machine). The entire construction is attached to the spindle housing. To generate the tool velocity the drive roller is mounted on the spindle. The wire tension is provided by a drive roll, which is mounted on a pneumatic cylinder with an integrated linear guide.

Thus, the arrangement of the rollers results in a tool length of $2.500 \mathrm{~mm}$. To minimize the influence of wire vibrations on the measurement, the measured value acquisition is performed at the drive roller. Moreover, the rotational velocity was measured using an inductive sensor on the drive roller.

For the experimental investigation, an inductive eddy current displacement sensor is used. The sensor has a measuring range of $4 \mathrm{~mm}$ and is usually used to measure the distance of planar ferromagnetic targets. Furthermore, the sensor has integrated evaluation electronics, thus no pre-processing of the signals is necessary [15]. In addition, the data acquisition was realized with an industrial PC, whereby the sampling rate of the sensor signal was $50 \mathrm{kHz}$. Due to the internal data processing of the selected sensor, no signal filtering was necessary.

To ensure the transferability of the measurement approach, the three different bonding matrices (Fig. 2) are considered. The specifications of the diamond wire tools used are described in Table 1.

\section{Functional verification on stationary and moving diamond wire tool}

At first, the basic functional verification was carried out on the stationary diamond wire tool (test rig 1). Figure 6 shows an example of the maximum normalized signal curves of the considered tools for a sensor distance of $1.5 \mathrm{~mm}$. As illustrated in the figure, all tools have a comparable signal
Table 1 Tool setup

\begin{tabular}{llll}
\hline & Tool 1 & Tool 2 & Tool 3 \\
\hline $\begin{array}{l}\text { Segment distance } l_{\mathrm{t}} \\
\quad[\mathrm{mm}]\end{array}$ & $25.1 * \pm 0.24$ & $19.0 \pm 0.65$ & $25.1 \pm 0.21$ \\
Segment length $l_{\mathrm{s}}[\mathrm{mm}]$ & $6.8 \pm 0.37$ & $4.2 \pm 0.45$ & $4.4 \pm 0.24$ \\
Diameter $d_{\mathrm{s}}[\mathrm{mm}]$ & $10.5 \pm 0.25$ & $10.2 \pm 0.46$ & $9.9 \pm 0.21$ \\
Bond matrix & Sintered & Vacuum-brazed & Galvanic \\
Segment/metre & 40 & 53 & 40 \\
\hline
\end{tabular}

Geometric values are own measurements (caliper gauge; standard deviation $\pm 3 \sigma$ )

curve. The parabolic shape is caused by the presence of a grinding segment in the measuring range, whereas the space in-between two grinding segments provides a constant signal of one. As is illustrated on the sintered diamond wire tool in Fig. 6 (tool 1), the geometric quantities $\left(l_{\mathrm{s}}, l_{\mathrm{t}}\right)$ introduced by Panhorst [1] are identifiable. Accordingly, the deviating signal curve of tool 2 compared to tools 1 and 3 can be explained by its different segment distances.

After the basic functional verification of the measuring principle has been carried out, the limit of the measuring range of the eddy current sensor used is considered. This is necessary because the specifications (datasheet) of the selected eddy current sensor apply to measurements on flat surfaces. In addition, knowledge about the measuring range is necessary because the distance between the sensor and the diamond wire tool can vary due to various factors during the grinding process (roll wear, grinding segment wear, etc.). The measuring range was determined on test rig 1 . For this purpose, the sensor was positioned at different distances above the stationary tools. The distance was increased in $0.5 \mathrm{~mm}$ steps from 0 to $4 \mathrm{~mm}$. The results

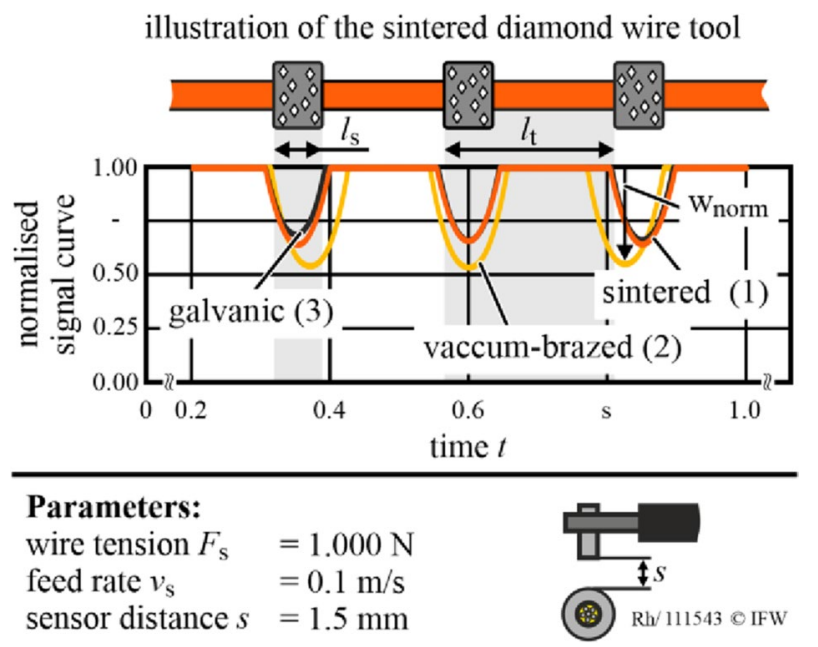

Fig. 6 Maximum value normalised signal curve 
show that the measuring ranges on the diamond wire tools are $50 \%$ lower than specified in the datasheet, which is due to the deviating geometry of the measured object. Furthermore, the results are independent of the bond matrix. In the next step, it will be investigated whether the selected approach can also ensure measurement of the moving diamond tool. Furthermore, it will be considered if the tool velocity influences on the signal of the eddy current sensor. It is also important that all grinding segments are detected to ensure robust monitoring subsequently. Finally, a real grinding process is carried out for the final functional verification. For this purpose, test rig 2 was utilized (Fig. 5) and tool 2 was selected. This is because it has 53 segments per meter and the smallest segment distance $l_{\mathrm{t}}$. So, it provides the highest measurement requirements. In relation to the tool length, 135 grinding segments were measured per tool rotation.

Figure 7 shows the influence of the tool velocity on the sensor signal. To determine the influence, the signal amplitudes of the grinding segments of ten tool rotations were arithmetically averaged. As the graph shows, there is no dependence of the sensor signal on the tool. Moreover, all grinding segments were detected regardless of the wire velocity.

Finally, the functional verification was successfully carried out in real grinding processes. For this purpose, dry rope grinding of steel (S355JR) was chosen as the machining process $\left(v_{\mathrm{s}}=18 \mathrm{~m} / \mathrm{s}\right.$, tool 2 , test rig 2$)$.

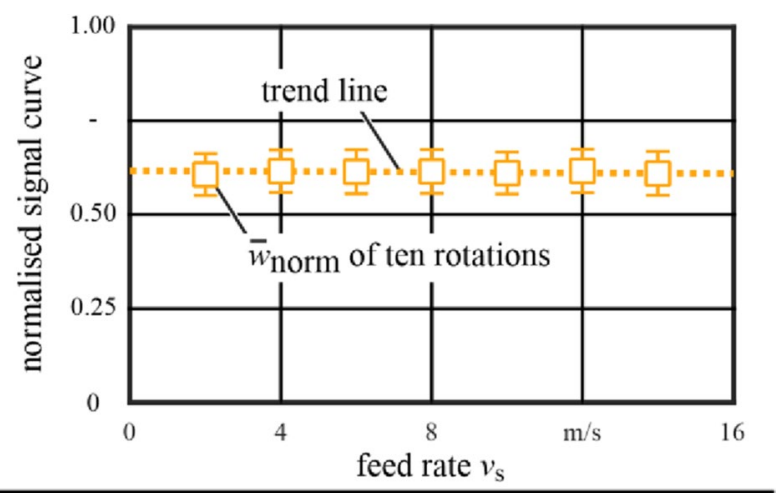

\begin{tabular}{ll}
\hline Parameters: & \\
wire tension $F_{\mathrm{S}}$ & $=1.000 \mathrm{~N}$ \\
sensor distance $s$ & $=1.5 \mathrm{~mm}$ \\
tool & $=$ vaccum-brazed \\
grinding segments & \\
per rotation & $=135$
\end{tabular}

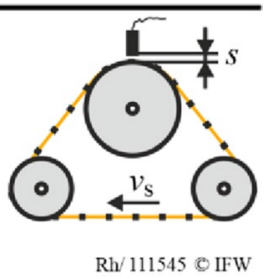

Fig. 7 Result of the velocity dependence of the sensor signal

\section{Fundamentals of the monitoring approach}

In general, monitoring features are extracted from measurable physical process variables. To be applicable, a feature must have a specific and functional correlation with the parameter to be monitored. Accordingly, after successful verification of the measurement approach, the monitoring feature is introduced. For this purpose, a suitable feature is the distance $l_{\mathrm{t}}$ between the grinding segments. This is because a change in $l_{\mathrm{t}}$ can be directly attributed to the displacement of a grinding segment. Due to the indirect measurement method, $l_{\mathrm{t}}$ cannot be measured directly. Therefore, the time difference between two grinding segments is used. The basic correlation between the two variables (time, distance) is given by the velocity.

$l=t \cdot v_{\mathrm{s}}$.

Therefore, Fig. 8 shows two approaches for generation the time-based feature. These are the segment duration $t_{\mathrm{t}}$ and the time interval between two minima $t_{\min }$. The segment duration $t_{\mathrm{t}}$ represents the time difference between the beginning of two consecutive grinding segments. To determine the times, the intersection point between a defined threshold value and the signal curve (falling signal) is determined in each case. In contrast, to determine $t_{\min }$, the respective extremes in the signal curve are determined. To minimize the influence of the signal noise, the measurement signal is smoothed by an average filter. Following this, the measured values are compared with each other. If the new value is smaller than the previous one, the new value is adopted. The minimum is identified as soon as the new value is greater than the previous value.

The determination of the segment duration $t_{\mathrm{t}}$ and the time interval between two minima $t_{\min }$ can be implemented in controls in a simple and low-computation manner. In addition, this reduces the costs for the required evaluation electronics. Compared to the state of the art, this enables real-time monitoring of the diamond wire tool.

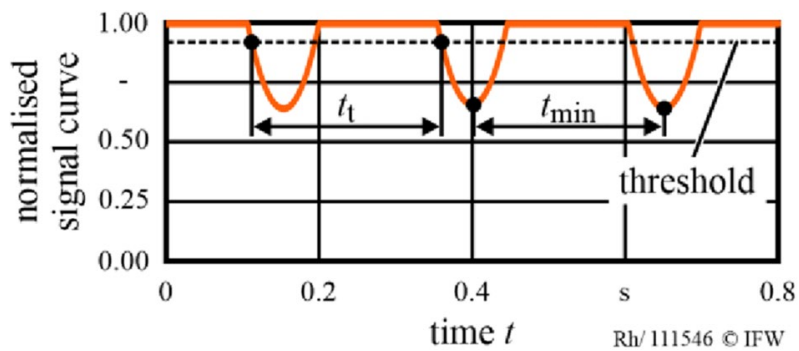

Fig. 8 Determination of the time difference 


\section{Experimental comparison of $t_{\mathrm{t}}$ and $t_{\min }$ and functional proof}

Since the eddy current displacement sensor is usually used for distance measurement, its signal is significantly dependent on the distance between the sensor and the measured object. Accordingly, the generation of $t_{\mathrm{t}}$ and $t_{\min }$ are examined for their robustness in relation to the sensor distance. To ensure defined and constant boundary conditions, test rig 1 was utilized for the experimental investigation. In addition, as the transferability of the measurement approach to the bonding matrices was demonstrated in chapter 4 , only one exemplary signal curve for three sensor distances of tool 1 is shown in Fig. 9. Furthermore, the threshold values considered are illustrated.

The results for the segment duration $t_{\mathrm{t}}$ and the time interval between two minima $t_{\min }$ are listed in Table 2. As shown in the table, the arithmetic average value of $t_{\mathrm{t}}$ is independent of the sensor distance and the selected threshold value. This is because only the respective falling signal curve is used for the calculation (Fig. 8). However, the standard deviation of $t_{\mathrm{t}}$ increases by a factor of 2.1 with increasing sensor distance. Moreover, the determination of $t_{\min }$ is also independent of the sensor distance (Table 2). Further, a dependence on the threshold value is not possible due to the formation value. The comparison between $t_{\mathrm{t}}$ and $t_{\min }$ also shows that both methods provide comparable results. However, the standard deviation of $t_{\min }$ is independent of the sensor distance. Furthermore, it is $22 \%$ lower on average than for $t_{\mathrm{t}}$.

After the suitability of $t_{\mathrm{t}}$ and $t_{\min }$ is demonstrated, their usability regarding the detection of displacing grinding segments is examined. For this purpose, an analog diamond wire tool was set up in which the distance between two grinding segments $l_{\text {dist }}$ can be varied systematically. It is based on the geometric data of tool 1 . Moreover, the tests were carried out on test rig 1 . Since there is no dependence

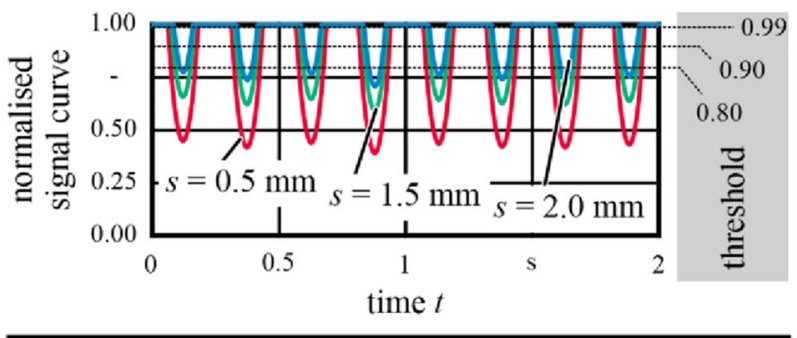

$\begin{array}{lll}\text { Parameters: } & & \\ \text { wire tension } F_{\mathrm{s}} & =1.000 \mathrm{~N} & \\ \text { feed rate } v_{\mathrm{s}} & =0.1 \mathrm{~m} / \mathrm{s} & \text { (2) } \mathrm{Rh} / 115470 \mathrm{FFW}\end{array}$

Fig. 9 Exemplary signal curve and chosen threshold values for comparison of the features generation
Table 2 Results of $t_{\mathrm{s}}$ and $t_{\min }$ on the (tool 1)

\begin{tabular}{llll}
\hline $\begin{array}{l}\text { Distance } s \\
{[\mathrm{~mm}]}\end{array}$ & Threshold value & $t_{\mathrm{t}}[\mathrm{ms}]$ & $t_{\min }[\mathrm{ms}]$ \\
\hline 0.5 & 0.99 & $250.31 \pm 8.17$ & $250.45 \pm 8.12$ \\
& 0.90 & $250.30 \pm 8.23$ & \\
& 0.80 & $250.30 \pm 8.68$ & \\
1.5 & 0.99 & $250.30 \pm 9.19$ & $250.44 \pm 8.14$ \\
& 0.90 & $250.31 \pm 9.78$ & \\
2.0 & 0.80 & $250.33 \pm 10.94$ & \\
& 0.99 & $250.30 \pm 10.22$ & $250.48 \pm 8.00$ \\
& 0.90 & $250.31 \pm 11.35$ & \\
& 0.80 & $250.29 \pm 17.25$ & \\
\hline
\end{tabular}

of the features on the sensor distance, the results are presented as an example for a sensor distance of $1.5 \mathrm{~mm}$. For determining $t_{\mathrm{t}}$ the selected threshold value was 0.99 . The experimental results are illustrated in Fig. 10.

The left graph shows the results for $t_{\mathrm{t}}$ and the right graph for $t_{\min }$. Furthermore, the calculated values for $t_{\mathrm{t}}$ and $t_{\min }$ are shown for three different $l_{\text {disp. }}$. Green represents the smallest displacement between two grinding segments, whereas red illustrates the results for a significantly displaced grinding segment. The grey areas in the graph show the results of the
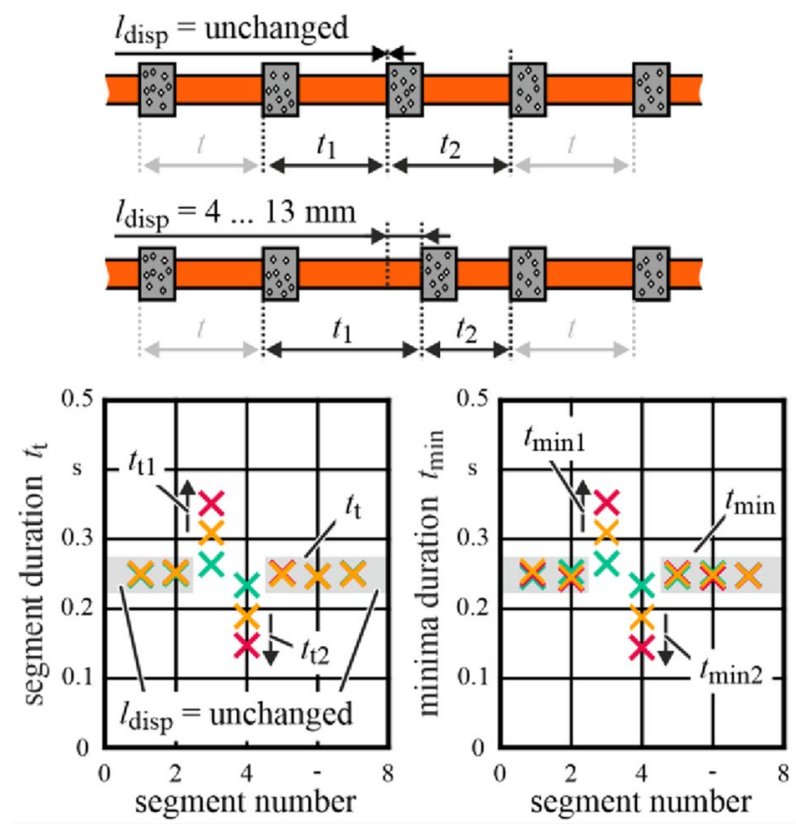

Parameters:

wire tension $F$

feed rate $v_{\mathrm{s}}$

tool

sensor distance $s$

$=1.000 \mathrm{~N}$

$=0.1 \mathrm{~m} / \mathrm{s}$

$=$ dummy

$=1.5 \mathrm{~mm}$

displacement segment $l_{\text {disp }}=4 ; 7 ; 13 \mathrm{~mm} \quad \mathrm{Rh} / 1115490 \mathrm{IFW}$

Fig. 10 Results for $t_{\mathrm{t}}$ and $t_{\min }$ of displacing grinding segments 
wire section with a constant $l_{\text {disp }}$. As can be seen from the results, both approaches allow the identification of a displacing grinding segment. The maximum standard deviation $( \pm 3 \sigma)$ of the segment duration $t_{\mathrm{t}}$ is $9.1 \mathrm{~ms}\left(l_{\mathrm{t}}=0.91 \mathrm{~mm}\right)$ and for $t_{\min } 8.8 \mathrm{~ms}\left(l_{\min }=0.88 \mathrm{~mm}\right)$. This means that reliable identification is possible on the stationary diamond wire tool.

After the basic functional verification has been carried out on the stationary wire, the next step is to carry out the functional verification on the moving wire (test rig 2). Moreover, the minimum displacement is investigated, from which reliable detection of a displaced grinding segment is possible. For the experiments, tool 2 was chosen again. Further, the tool was prepared so that a grinding segment could be moved on the carrier wire. For this purpose, the steel spring behind the grinding segment was removed. Thus, the distance $l_{\mathrm{t}}$ can be defined and freely adjusted. To ensure that the set distance $l_{\mathrm{t}}$ does not change during the experiment, the grinding segment was fixed with adhesive.

The results for $t_{\min }$ are presented in Fig. 11 for different displaced grinding segments at a velocity of $20 \mathrm{~m} / \mathrm{s}$. The arithmetic mean values of non-displaced grinding segments are illustrated in green for reference. The red curve presents the determined time duration $\left(t_{\min 1}\right)$ in front of the movable grinding segment. In contrast, the yellow measuring points represent the time duration $\left(t_{\min 2}\right)$ behind the movable grinding segment.

As can be seen from Fig. 11, a displaced grinding segment can be identified. If the distance increases, the arithmetic mean of the determined time duration $t_{\min 1}$ (red) also increases. At the same time, the calculated time duration $t_{\min 2}$ (yellow) between the displaced grinding segment and the following fixed grinding segment is reduced by the same
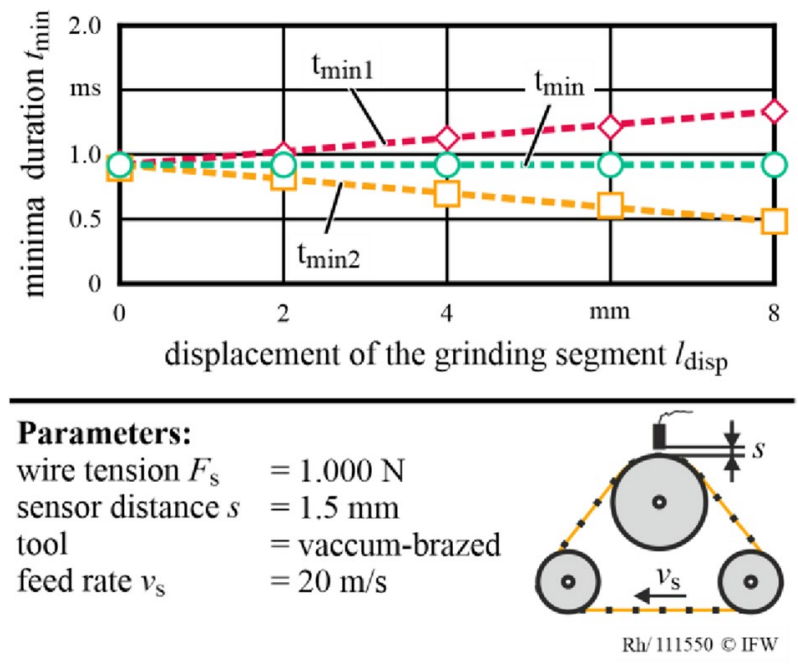

Fig. 11 Results of $t_{\min }$ with different displaced grinding segments at moving tool quantity. This relationship is consistent with the results in Fig. 10. Furthermore, the maximum standard deviation $( \pm 3 \sigma)$ for $t_{\min }$ is $46.8 \mu \mathrm{s}$. Thus, a deviation of the segment distance $l_{\mathrm{t}}$ can be reliably detected from a displacement of $2 \mathrm{~mm}$. In contrast, the maximum standard deviation $( \pm 3 \sigma)$ for $t_{\mathrm{t}}$ is $63.8 \mu \mathrm{s}$. Thus, robust identification by $t_{\mathrm{t}}$ is only possible from a displacement of $4 \mathrm{~mm}$. Accordingly, $t_{\min }$ will be used to determine the features for further studies.

\section{Monitoring approach}

Corresponding to the presented results, the monitoring approach in Fig. 12 is shown. To account for productionrelated variance, the actual value of the segment duration $t_{\mathrm{t}}$ or $t_{\min }$ is compared with a moving average value subject to a tolerance band. If the limits are exceeded, this can be attributed to displacement of the grinding segments. During the cutting process, slippage can occur between the drive wheel and the diamond wire tool because of low wire tension. This influences the considered features $t_{\mathrm{t}}$ and $t_{\mathrm{min}}$. Accordingly, the occurrence of wire slips must be taken into account for robust monitoring. If not accounted for, false alarms will

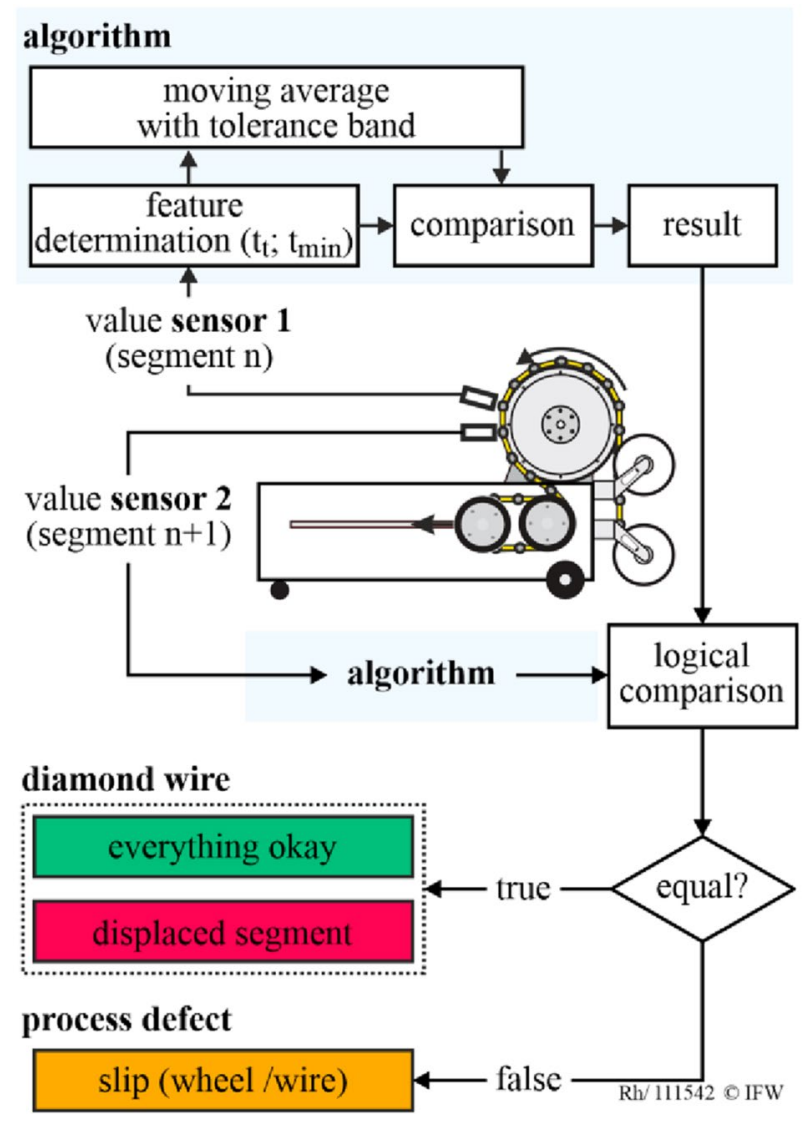

Fig. 12 Monitoring approach: tool assembly and wire slip 
occur. A more effective approach is utilizing a second offset eddy current sensor (Fig. 12). If grinding segments are displaced, both sensors detect significant deviations in $t_{\mathrm{t}}$ or $t_{\text {min }}$. In the case of slippage, the results do not match. Consequently, the presented approach can be used to monitor both the tool and the slippage.

\section{Conclusion and outlook}

Within the present paper, a novel measurement and monitoring approach the tool monitoring in diamond wire grinding was presented. First, a suitable measurement approach was introduced. Due to the requirements of the process, an inductive measuring method was chosen. Its functional verification was subsequently carried out using the three common bonding matrices. Afterward, a feature for monitoring the grinding segment distance was presented. It was shown that two approaches, segment duration $t_{\mathrm{t}}$ and time interval between two minima $t_{\min }$, are suitable for monitoring the diamond wire tool during the sawing process. Finally, it was demonstrated that the feature enables the detection of displacing grinding segments (prepared diamond wire tool).

In further work, the presented monitoring approach will be investigated during the cutting process. Furthermore, the influence of the wire connector will be investigated to ensure robust monitoring of the grinding segment distance.

Acknowledgements The research project "All-electric mobile wire saw" is funded by the Federal Ministry for Economic Affairs and Energy (BMWi) as part of the Central SME Innovation Programme (ZIM) and supervised by the Federation of Industrial Research Associations (AiF). The IFW and the cooperation partner Cedima Diamantwerkzeug- und Maschinenbaugesellschaft $\mathrm{mbH}$ would like to thank you for the financial support in this project.

Funding Open Access funding enabled and organized by Projekt DEAL.

Open Access This article is licensed under a Creative Commons Attribution 4.0 International License, which permits use, sharing, adaptation, distribution and reproduction in any medium or format, as long as you give appropriate credit to the original author(s) and the source, provide a link to the Creative Commons licence, and indicate if changes were made. The images or other third party material in this article are included in the article's Creative Commons licence, unless indicated otherwise in a credit line to the material. If material is not included in the article's Creative Commons licence and your intended use is not permitted by statutory regulation or exceeds the permitted use, you will need to obtain permission directly from the copyright holder. To view a copy of this licence, visit http://creativecommons.org/licenses/by/4.0/.

\section{References}

1. Panhorst HJ (1974) Seilsägen von granit mit diamantwerkzeugen - systematische entwicklung eines trennwerkzeuges. Dissertation, Technische Universität Hannover

2. Steiner H Dismantling and demolition processes and technologies in nuclear decommissioning projects (2012) Nuclear decommissioning - planning, execution and international experience. Elsevier

3. Bach F-W, Pfeifer W, Versemann R et al (2005) Decommissioning technologies, including recent developments and special features of the dismantling of nuclear research and prototype facilities. Kerntechnik 70:31-46. https://doi.org/10.3139/124.100223

4. Vogt B (2002) Bow of the Kursk cut with 'diamond chain'. Indust Diamanten Rund (IDR) 594:151-154

5. Tönshoff HK, Denkena B, Apmann HH (2003) Diamond tools for wire sawing metal components. KEM 250:33-40

6. Tatzig L (2018) Trockenes Seilschleifen von Stahl. Dissertation, Leibniz Universität Hannover

7. Knecht D (2015) Untersuchungen zum Seilsägeprozess an Stählen ausgewählter Geometrien im umschlingenden Verfahren. Dissertation, Karlsruher Institut für Technologie

8. Tyrolit HAG (2003) Safety manual system description: diamond wire saws. https://www.tyrolit.at/fileadmin/Documents/Const ruction/Safetysheets/Wire_Sawing/SHB_Seilsaegen_EN.pdf. (Accessed 01 Jul 2021)

9. Denkena B, Grove T, Tatzig L (2017) Mechanical and thermal tool loads in dry diamond wire sawing of steel. In: 13th international symposium "conditioning of radioactive operational and decommissioning wastes", pp 324-330

10. Linke B (2016) Manufacturing and sustainability of bonding systems for grinding tools. Prod Eng Res Devel 10:265-276. https:// doi.org/10.1007/s11740-016-0668-5

11. Huang GQ, Xu XP (2006) Analysis of the breakage of diamond wire saws in sawing of stone. KEM 304-305:123-126

12. Tantussi G, Lanzetta M, Gentile S et al. (2008) Diamond wire cutting: failure modes, risks for safety and workers' protection. In: second international congress dimension stones (ICDS) XXI century challenges, Carrara (MS)

13. Yarahmadi R, Bagherpour R, Khademian A (2014) Safety risk assessment of Iran's dimension stone quarries (exploited by diamond wire cutting method). Saf Sci 63:146-150. https://doi.org/ 10.1016/j.ssci.2013.11.003

14. Apmann H (2004) Seilschleifen von metallischen und mineralischen Werkstoffen. Dissertation, Leibniz Universität Hannover

15. Micro-Epsilon M (2021) Inductive sensors based on eddy currents: eddyNCDT 3001. https://www.micro-epsilon.com/downl oad/products/cat-eddy/dax--eddyNCDT-3001--en-us.html\#page= 2\&zoom=Fit. (Accessed 02 Jul 2021)

Publisher's Note Springer Nature remains neutral with regard to jurisdictional claims in published maps and institutional affiliations. 